Indexed by

\title{
Scopus
}

\section{MACHINABILITY STUDY AND OPTIMIZATION OF TOOL LIFE AND SURFACE ROUGHNESS OF FERRITE - BAINITE DUAL PHASE STEEL}

Crossref

KOBSON

gil Google

\section{Ananda Hegde}

Department of Mechanical and Manufacturing Engineering, Manipal Institute of Technology, Manipal Academy of Higher Education, Manipal-576104, Karnataka, India

\section{Sathyashankara Sharma}

Department of Mechanical and Manufacturing Engineering, Manipal Institute of Technology, Manipal Academy of Higher Education, Manipal-576104, Karnataka, India

\section{Jamaluddin Hindi}

Department of Mechanical and Manufacturing Engineering, Manipal Institute of Technology, Manipal Academy of Higher Education, Manipal-576104, Karnataka, India

\section{Gurumurthy BM}

Department of Mechanical and Manufacturing Engineering, Manipal Institute of Technology, Manipal Academy of Higher Education, Manipal-576104, Karnataka, India

Key words: ferrite, bainite, tool life, surface roughness, dual phase doi:10.5937/jaes0-32927

Cite article:

Hegde A., Hindi J., Gurumurthy BM., Sharma S., Ki A. (2022) MACHINABILITY STUDY AND OPTIMIZATION OF TOOL LIFE AND SURFACE ROUGHNESS OF FERRITE - BAINITE DUAL PHASE STEEL, Journal of Applied Engineering Science, 20(2), 358 - 364, DOI:10.5937/ jaes032927

Online aceess of full paper is available at: www.engineeringscience.rs/browse-issues 


\title{
MACHINABILITY STUDY AND OPTIMIZATION OF TOOL LIFE AND SURFACE ROUGHNESS OF FERRITE - BAINITE DUAL PHASE STEEL
}

\author{
Ananda Hegde, Jamaluddin Hindi, Gurumurthy BM*, Sathyashankara Sharma, Achutha Ki \\ Department of Mechanical and Manufacturing Engineering, Manipal Institute of Technology, Manipal \\ Academy of Higher Education, Manipal-576104, Karnataka, India
}

Aim of this present research work is to obtain the machining parameters to optimize the tool life and surface roughness for ferrite-bainite dual phase steel. Machinability tests are carried out using orthogonal array of 27, the Taguchi method, in which the machining parameters are considered as control factors. The effect of speed, feed and depth of cut on tool life and surface roughness of dual phase structure steel is analysed using ANOVA. Regression analysis is used to obtain the equations for predicting the tool life and surface roughness. Experiment is conducted using uncoated carbide insert tool by varying the process parameters. Optimum tool life and surface is analysed using Response Surface Methodology. Hardness and microstructure revealed the dual phase condition in different intercritical zones. It is found that hardness improves as the intercritical temperature is increased from 750 to $770^{\circ} \mathrm{C}$. Experimental results prove that dual phase structure has better machining characteristics at an intercritical temperature of $750^{\circ} \mathrm{C}$.

Key words: ferrite, bainite, tool life, surface roughness, dual phase

\section{INTRODUCTION}

Machinability is a complex concept and it is not possible to express it in universal unit. However, while quantifying the machinability of the material, it has to be done using any one of the quantifying methods. Generally used criterion to determine machinability is the tool life method. In this method, how long the tool lasts before reaching the limiting (critical) value of flank wear is noted. The time taken by the tool to reach the specific flank wear as established by the ISO 3685 standard is taken as the Tool Life (TL). In the power consumption method, cutting forces during the machining are measured using dynamometer. Using the measured cutting forces, power consumed for the removal of the unit volume of the material is determined. Another criterion used to quantify the machinability is surface finish obtained, in which Surface Roughness (SR) of the machined material is measured using instruments like Profilometer [1]. Sometimes, the nature of chip formed during the machining is also used to express the machinability. Though it is not possible to quantify the machinability with this method, the nature of chips formed may be compared and related to the material properties. Machinability depends on several parameter like cutting force, speed, feed depth of cut and its hardness [2, 3]. As this dual phase steel has wide range applications due to its good mechanical properties, machining operation needs to be carried out prior to its use. Because of the high hardness, tool life may not be long and it may be difficult to machine it. Hence, it is important to assess the machinability of ferrite -bainite dual phase steel. This will be helpful in selecting the proper machining parameters to machine it successfully. Machinability is mainly dependent on the type of tool and nature of tool failure, work piece surface structure and its behaviour in operating condition [4-6]. As steels are among the most widely used engineering materials, manufacturing researchers have extensively studied their machinability. In this field of research, countless attempts have been made to model tool life and machinability to provide a better understanding of metal cutting operations [7]. N. $\mathrm{K}$. Dhar, et al. [8] in their study, reported the influence of cryogenic cooling involving a liquid nitrogen jet on various process parameters like, chip-tool interface temperature, SR, tool flank wear behavior and dimensional accuracy by turning hardened AISI4140 steel. Results manifested that cryogenic cooling had a significant effect on dimensional accuracy and improved its TL and reduced SR. I. Asiltürk and H. Akkus [9] used Taguchi method to get the optimum cutting parameters like speed, feed, and DoC, which were further used to minimize $S R$ ( $R a$ and $R z$ ) values. ANOVA was used to examine the experimental results. Optimum values of speed, feed and DoC were obtained using L9 orthogonal array and were loaded in CNC. Tests were conducted on AISI4140 steel, in hardened and untreated conditions. Coated carbide cutting tool was used in dry machining on CNC. To ensure the correct SR values for each experiment a new tool insert was used. Mathematical tools like Signal to noise ratio $(\mathrm{S} / \mathrm{N})$ and ANOVA using Taguchi method was used to understand the effect of different cutting conditions on SR values. Experimentation revealed that feed had a notable effect on SR (Ra and Rz) as high as $95 \%$. Cutting parameters, which gave the optimum values of $R a$ and $R z$, were observed to be $120 \mathrm{~m} / \mathrm{min}, 0.18 \mathrm{~mm} / \mathrm{rev}$ and 0.4 $\mathrm{mm}$ as CS, feed and DoC respectively. P. L. Anand, et al. [10] studied the single response optimization of turning parameters for AISI1040 steel to optimize SR and tool tip temperature in turning operations using single point carbide cutting tool. Optimum values of speed and DoC 
were obtained using L9 orthogonal array. ANOVA was employed to analyze the effects of process parameters during turning. Mathematical tools like signal to noise ratio $(\mathrm{S} / \mathrm{N})$ and variance were analyzed using Taguchi method to understand the effect of different machining parameters on SR and tool tip temperature values. Experimentation revealed that $\mathrm{SR}$ was directly proportional to speed but inversely to DoC and tool tip temperature was directly proportional to both speed and DoC. However, not many reports are available regarding the machining behavior of ferrite-bainite dual phase steel. As this material is being used in wide range of application, understanding its machining behavior would immensely help the manufacturer. In this study, machinability in terms of tool life and surface roughness for the ferrite-bainite dual phase steel is determined. Also, in order to get the optimum combination of tool life and surface roughness, machining parameters are obtained.

\section{Heat treatment procedure}

As bought specimen is first normalized and later subjected to dual phase treatment as per the details given in the table 2.

\section{MATERIAL AND METHODOLOGY}

\section{AISI 1040 steel}

Table 1: Prominent alloying elements of the medium carbon AISI 1040

\begin{tabular}{|c|c|c|c|c|c|c|c|}
\hline \multicolumn{7}{|c|}{ Wt.\% } \\
\hline $\begin{array}{c}\text { Type } \\
\text { Steel }\end{array}$ & $\mathrm{C}$ & $\mathrm{Mn}$ & $\mathrm{Si}$ & $\mathrm{Cr}$ & $\mathrm{Mo}$ & $\mathrm{Ni}$ & $\mathrm{Fe}$ \\
\hline $\begin{array}{c}\text { AISI } \\
1040\end{array}$ & 0.39 & 0.72 & 0.10 & 0.03 & 0.02 & 0.02 & Balance \\
\hline
\end{tabular}

The machinability of the heat treated samples was assessed in terms of tool life and surface roughness value. The machinability tests were carried out as per the procedure specified in ISO 3685 . The test specimens were prepared by machining the round bars of bars of medium carbon low alloy. The dimension of the machinability test specimen is as per the ISO 3685 standard and the details are shown in the Figure 1.

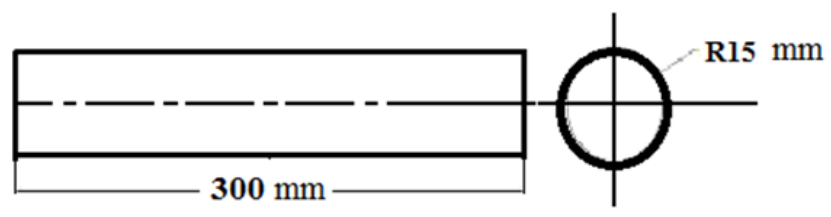

Figure 1: Test specimen details for machinability test

Table 2: Heat treatment chart

\begin{tabular}{|c|c|c|c|c|c|}
\hline & \multicolumn{4}{|c|}{ Normalizing } & Normalizing \\
\hline $\begin{array}{l}\text { Heating } \\
\text { temperature }\end{array}$ & Soaking time & $\begin{array}{l}\text { Heating in salt bath } \\
\text { temperature }\end{array}$ & Soaking time & Cooling & $\begin{array}{l}\text { Heating temperature and } \\
\text { cooling method }\end{array}$ \\
\hline $750^{\circ} \mathrm{C}$ & $2 \mathrm{~h}$ & $350^{\circ} \mathrm{C}$ & 30 minutes & Air cooling & Temperature $-900^{\circ} \mathrm{C}$ \\
\hline $770^{\circ} \mathrm{C}$ & $2 \mathrm{~h}$ & $350^{\circ} \mathrm{C}$ & 30 minutes & Air cooling & Soaking time $-2 \mathrm{~h}$ \\
\hline $790^{\circ} \mathrm{C}$ & $2 \mathrm{~h}$ & $350^{\circ} \mathrm{C}$ & 30 minutes & Air cooling & Cooling - Air cooling \\
\hline
\end{tabular}

\section{Machinability test}

The machinability tests were carried out on the heat treated round bars of medium carbon low alloy AISI $1040,(\phi 30 \mathrm{~mm} \times 300 \mathrm{~mm})$ according to ISO 3685 [11] in a CNC turning center. No cutting fluid was used during the machining process. The turning process was stopped at equal intervals of time to check the tool flank wear using the tool makers microscope. This was continued till the tool flank wear reached a specific value, as given by the ISO 3685 standard and surface roughness by using ISO 4287 [12]. The time taken to obtain this tool flank wear was noted. The carbide insert VNMG12t304 with carbide grade of WK20CT ( HC K20) was used for machining and average flank wear land (VBB) of $0.3 \mathrm{~mm}$ was used to determine the tool life as established by ISO 3685 standard. Similarly

\section{Design of Experiments (DOE)}

In order to plan the experiments systematically and economically, design of experiments (DOE) was used for obtaining the details regarding carrying out the various tests. It also helps in statistically analysing the results and determining the effect of process variables on the responses. In the current study, the machinability experiments were carried out by varying the machining and heat treatment parameters in order to determine the effect of these factors on the tool life and surface roughness of the material [14]. The design of experiment was used to obtain details of the various experiment trails to be conducted. The details of all the factors involved in the machinability test are shown in the Table 3.

\section{Table 3: Details of control factors for machinability test}

\begin{tabular}{|c|c|c|c|}
\hline Control Factors & Level 1 & Level 2 & Level 3 \\
\hline Temperature $\left({ }^{\circ} \mathrm{C}\right)$ & 750 & 770 & 790 \\
\hline Speed $(\mathrm{m} / \mathrm{min})$ & 800 & 1150 & 1500 \\
\hline Feed rate $(\mathrm{mm} / \mathrm{rev})$ & 0.2 & 0.4 & 0.6 \\
\hline Depth of Cut $(\mathrm{mm})$ & 0.13 & 0.15 & 0.18 \\
\hline
\end{tabular}




\section{RESULT AND DISCUSSION}

\section{Microstructure}

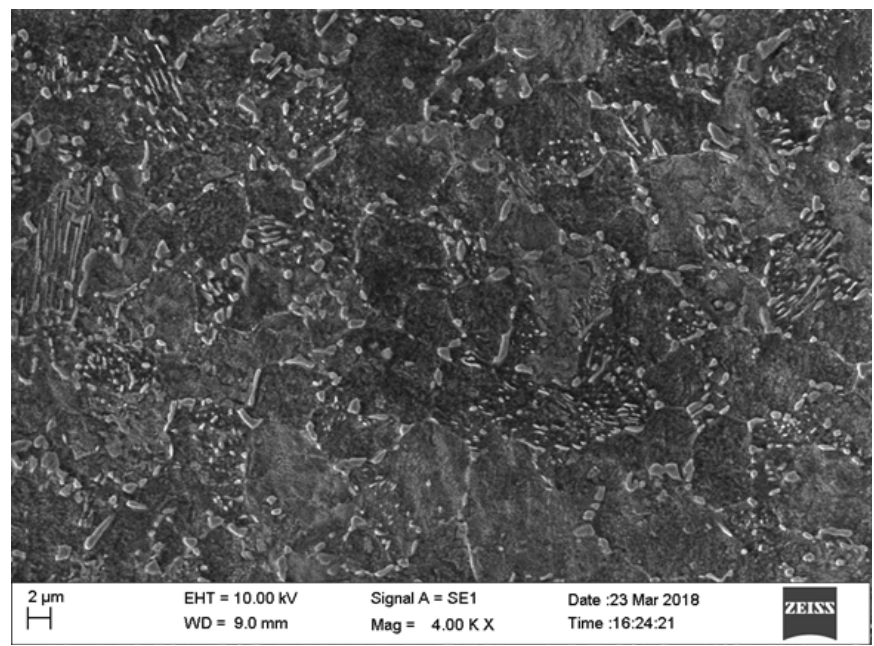

(a)

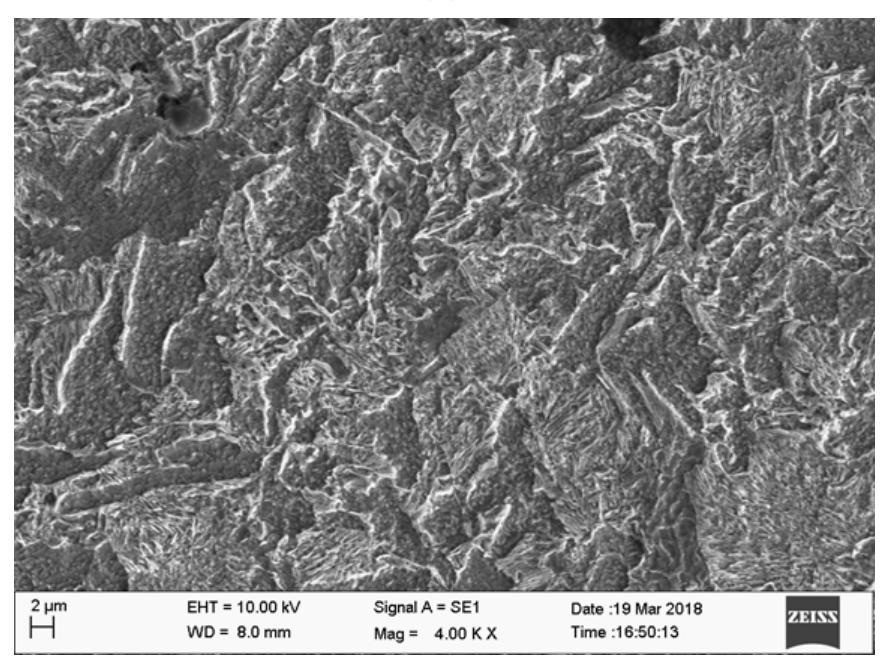

(b)

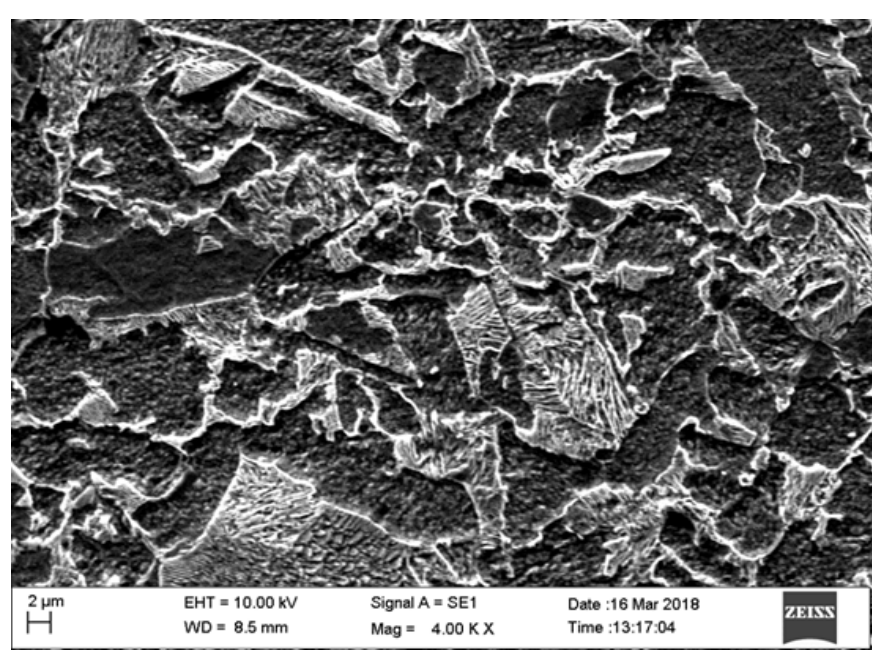

(c)

Figure 2: Microstructure analysis of

a) intercritical temperature at $750^{\circ} \mathrm{C}$ b) $770{ }^{\circ} \mathrm{C}$

c) $790{ }^{\circ} \mathrm{C}$
Table 4: Hardness of ferrite-bainite dual phase steel

\begin{tabular}{|c|c|c|c|}
\hline Temperature & Trial 1 & Trial 2 & Trial 3 \\
\hline $750^{\circ} \mathrm{C}$. & 30 & 32 & 31 \\
\hline $770^{\circ} \mathrm{C}$. & 35 & 36 & 35 \\
\hline $790^{\circ} \mathrm{C}$. & 48 & 49 & 48 \\
\hline
\end{tabular}

The SEM micrographs of DPS showed the microstructure that consists of mainly ferrite and bainite of steel samples, as shown in figures $2(a, b$ and $c)$. During the dual phase (F-B) treatment, the nature and quantity of ferrite and bainite phases are varying with respect to heat treatment temperatures. In all the DPS, the microstructure at higher temperature $\left(790^{\circ} \mathrm{C}\right)$ shows more bainitic phases compared to other two temperatures $\left(750\right.$ and $\left.770{ }^{\circ} \mathrm{C}\right)$. With the increase in intercritical temperature, the wt.\% of austenite grain increases that enlarges grain size of austenite. On bainitic transformation, the same austenite transforms into lower bainite, showing fine distribution of ferrite and cementite in the colonies [15]. Hence, at $790^{\circ} \mathrm{C}$, uniform bainite phase is observed in all the steel categories with traces of fine-grained pro eutectoid ferrite. The effect of variation in intercritical temperature on the hardness of the steel is shown in table 4. It may be seen that, increase in the temperature has resulted in the improvement in hardness by considerable amount.

\section{$T_{L}$ and $S_{R}$ of AISI1040 F-B DPS}

Table 5 provides the $T_{L}$ and $S_{R}$ of AISI1040 F-B DPS at different temperatures and different machining parameters. Minitab is used to analyze the effect of CS, feed and DoC on $T_{L}$ and $S_{R}$ of F-B DPS.

\section{Statistical analysis}

ANOVA technique is used to analyze the relative contribution of each factor on $T_{L}$ and $S_{R}$.

\section{ANOVA for $T_{L}$ and $S_{R}$ of AISI1040 F-B DPS}

ANOVA carried out, initially with all the four factors together with their interactions and it is found that all linear terms had more than $98 \%$ contribution for TL and SR. The technique is carried out at $5 \%$ significance level using only the linear terms to obtain the relative contribution of the four factors on the $T_{L}$ and $S_{R}$. Tables 6 and 7 show the ANOVA results for TL and SR of AISI1040 F-B DPS respectively. The SEM micrographs of dual phase treated steels showed that the microstructure consists of mainly ferrite and bainite. During the dual phase (F-B) treatment, the nature and quantity of ferrite and bainite phases are varying with respect to heat treatment temperature. In all the DPS ,the microstructure at higher $\left(790^{\circ} \mathrm{C}\right.$ ) temperature shows more bainitic phases compared to other two lower temperatures $\left(750\right.$ and $\left.770{ }^{\circ} \mathrm{C}\right)$. 
Table 5: $T_{L}$ and $S_{R}$ of AlSI1040 F-B DPS

\begin{tabular}{|c|c|c|c|c|c|c|}
\hline SI No & Temperature $\left({ }^{\circ} \mathrm{C}\right)$ & Speed $(\mathrm{m} / \mathrm{min})$ & Feed $(\mathrm{mm} / \mathrm{rev})$ & DoC $(\mathrm{mm})$ & $\mathrm{T}_{\mathrm{L}}(\mathrm{s})$ & $\mathrm{S}_{\mathrm{R}}(\mu \mathrm{m})$ \\
\hline 1 & 750 & 80 & 0.13 & 0.2 & 2680 & 4.31 \\
\hline 2 & 750 & 80 & 0.13 & 0.2 & 2628 & 4.23 \\
\hline 3 & 750 & 80 & 0.13 & 0.2 & 2630 & 4.25 \\
\hline 4 & 750 & 115 & 0.15 & 0.4 & 1906 & 3.90 \\
\hline 5 & 750 & 115 & 0.15 & 0.4 & 1909 & 4.18 \\
\hline 6 & 750 & 115 & 0.15 & 0.4 & 1906 & 4.17 \\
\hline 7 & 750 & 150 & 0.18 & 0.6 & 993 & 2.62 \\
\hline 8 & 750 & 150 & 0.18 & 0.6 & 998 & 2.57 \\
\hline 9 & 750 & 150 & 0.18 & 0.6 & 991 & 2.68 \\
\hline 10 & 770 & 80 & 0.15 & 0.6 & 1468 & 4.02 \\
\hline 11 & 770 & 80 & 0.15 & 0.6 & 1456 & 4.08 \\
\hline 12 & 770 & 80 & 0.15 & 0.6 & 1468 & 4.11 \\
\hline 13 & 770 & 115 & 0.18 & 0.2 & 2150 & 3.03 \\
\hline 14 & 770 & 115 & 0.18 & 0.2 & 2180 & 3.10 \\
\hline 15 & 770 & 115 & 0.18 & 0.2 & 2175 & 3.20 \\
\hline 16 & 770 & 150 & 0.13 & 0.4 & 1193 & 2.50 \\
\hline 17 & 770 & 150 & 0.13 & 0.4 & 1156 & 2.56 \\
\hline 18 & 770 & 150 & 0.13 & 0.4 & 1167 & 2.61 \\
\hline 19 & 790 & 80 & 0.18 & 0.4 & 1530 & 3.20 \\
\hline 20 & 790 & 80 & 0.18 & 0.4 & 1529 & 3.10 \\
\hline 21 & 790 & 80 & 0.18 & 0.4 & 1526 & 3.02 \\
\hline 22 & 790 & 115 & 0.13 & 0.6 & 698 & 2.32 \\
\hline 23 & 790 & 115 & 0.13 & 0.6 & 697 & 2.45 \\
\hline 24 & 790 & 115 & 0.13 & 0.6 & 705 & 2.49 \\
\hline 25 & 790 & 150 & 0.15 & 0.2 & 1299 & 2.22 \\
\hline 26 & 790 & 150 & 0.15 & 0.2 & 1298 & 2.24 \\
\hline 27 & 790 & 150 & 0.15 & 0.2 & 1295 & 2.20 \\
\hline & & & & & & \\
\hline
\end{tabular}

Table 6: ANOVA for $T_{L}$ of AISI1040 F-B DPS

\begin{tabular}{|c|c|c|c|c|c|}
\hline Factors & Degree of freedom & Seq sum of square & Adj MS & $\mathrm{P}$ & $\%$ Contribution \\
\hline Temperature $\left({ }^{\circ} \mathrm{C}\right)$ & 2 & 2258094 & 1129047 & $<0.001$ & 24.82 \\
\hline Speed $(\mathrm{m} / \mathrm{min})$ & 2 & 2430417 & 1215208 & $<0.001$ & 26.70 \\
\hline Feed $(\mathrm{mm} / \mathrm{rev})$ & 2 & 30310 & 15155 & $<0.001$ & 0.33 \\
\hline DoC $(\mathrm{mm})$ & 2 & 4364514 & 2182257 & $<0.001$ & 47.95 \\
\hline Error & 18 & 19654 & 1092 & & \\
\hline Total & 26 & 9102988 & & & \\
\hline
\end{tabular}

Speed is the major contributing factor on the variation in surface roughness. Thermal softening of the material at higher cutting speed may have varied the surface roughness considerably. Depth of cut was found to be the major contributing factor on the variation of tool life. Temperature has 24.82 and $35.09 \%$ contribution on TL and SR due to increase in intercritical temperature and the wt.\% of austenite phase. With increase in the amount of austenite at higher temperature $\left(790^{\circ} \mathrm{C}\right)$ more amount of bainite is formed, which leads to lesser TL due to higher hardness and strength. It is seen that speed is having 26.70 and $54.70 \%$ contribution on TL and SR respectively. Lower speed shows higher TL, higher speed having better surface finish. But DoC has more effect on TL $(47.95 \%)$ and least effect on SR $(1.45 \%)$. Feed has low effect on TL $(0.33 \%)$ and SR $(8.39 \%)$. 
Table 7: ANOVA for $S_{R}$ of AISI1040 F-B DPS

\begin{tabular}{|c|c|c|c|c|c|}
\hline Factors & Degree of freedom & Seq sum of square & Adj MS & $\mathrm{P}$ & \% Contribution \\
\hline Temperature $\left({ }^{\circ} \mathrm{C}\right)$ & 2 & 5.2904 & 2.64518 & $<0.001$ & 35.09 \\
\hline Speed $(\mathrm{m} / \mathrm{min})$ & 2 & 8.1857 & 4.09286 & $<0.001$ & 54.29 \\
\hline Feed $(\mathrm{mm} / \mathrm{rev})$ & 2 & 1.2652 & 0.63259 & $<0.001$ & 8.39 \\
\hline DoC $(\mathrm{mm})$ & 2 & 0.2183 & 0.10917 & $<0.001$ & 1.45 \\
\hline Error & 18 & 0.1177 & 0.00654 & & \\
\hline Total & 26 & 15.0773 & & & \\
\hline
\end{tabular}

Regression analysis for $T_{L}$ and $S_{R}$ of AISI1040 F-B DPS

Regression equations are used to predict the TL and SR by considering the four factors and its range. Equations 1 and 2 give the regression equations of TL and SR respectively.

$T_{L}=17108-17.578$ Temp -10.357 Speed +1003 Feed -2461.4 DoC

$S_{R}=26.80-0.02686$ Temp -0.01924 Speed -3.80 Feed -0.400 DoC

The R-squared values for the regression models are:

R-squared model for $\mathrm{T}_{\mathrm{L}}$ :

R-squared $=98.47 \%$

$\mathrm{R}-\mathrm{Sq}(\mathrm{Adj})=98.19 \%$

R-squared model for SR:

R-squared $=90.84 \%$

R- Sq $($ Adj $)=88.70 \%$

The R-Sq(Adj) values $98.19 \%$ for TL and $88.70 \%$ for SR indicate that the regression equation possesses a good fit with the results of the actual experiments conducted. Predictions of TL and SR have been analyzed through control factors.

\section{Error analysis for $T_{L}$ and $S_{R}$ of AISI1040 F-B DPS}

Statistical analysis is validated using regression equations to confirm the test results. Actual test results of $T_{L}$ and $S_{R}$ are compared with the predicted results of regression equations. Difference between the actual and predicted results is given as the \% Error. Figures 3 and figure 4 provide the detailed error analysis for $T_{L}$ and $S_{R}$ of AISI1040 F-B DPS. From the error analysis for TL and SR (figures 3 and 4), it is observed that predicted and actual results are approximately same for all the test trials. Variation in predicted and actual results are minimal and it is confirmed from the R-Square values obtained for $T_{L}$ and $S_{R}$. The experimental results recorded prove that, regression equations obtained for this study may be used to predict $T_{L}$ and $S_{R}$ values. Maximum $T_{L}$ and lower $S R$ are the requirements for good machinability. By combining $T_{L}$ and $S_{R}$ better machinability can be obtained.

Figure 5 shows the detailed response optimization of $T_{L}$ and $S_{R}$ values. From the results, in order to obtain the

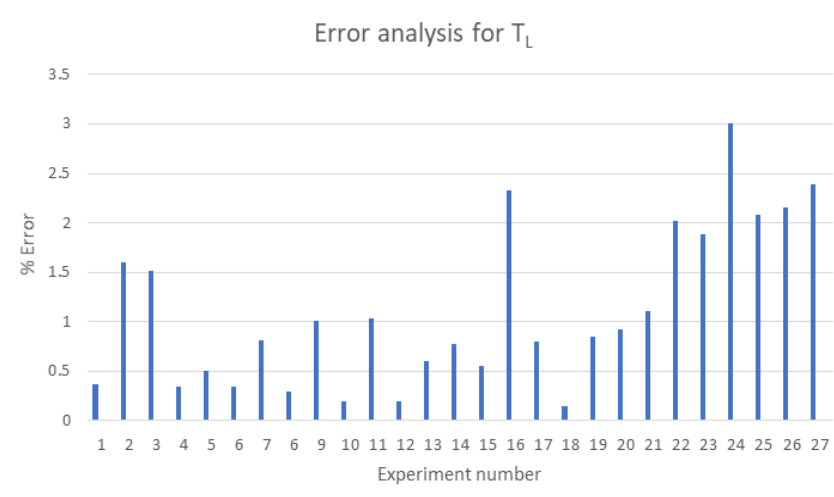

Figure 3: Error analysis for $T_{L}$ of AISI1040 F-B DPS

Error analysis for $S_{R}$

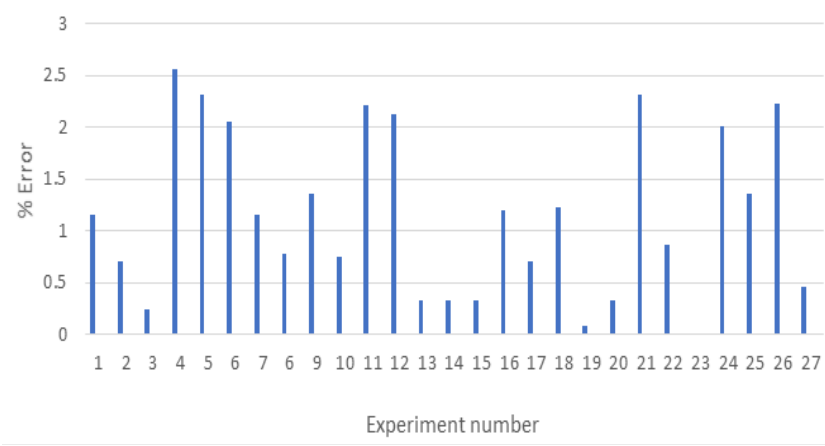

Figure 4: Error analysis for $S_{R}$ of AISI1040 F-B DPS

\section{Optimization of process parameters for AISI1040 F-B steel}

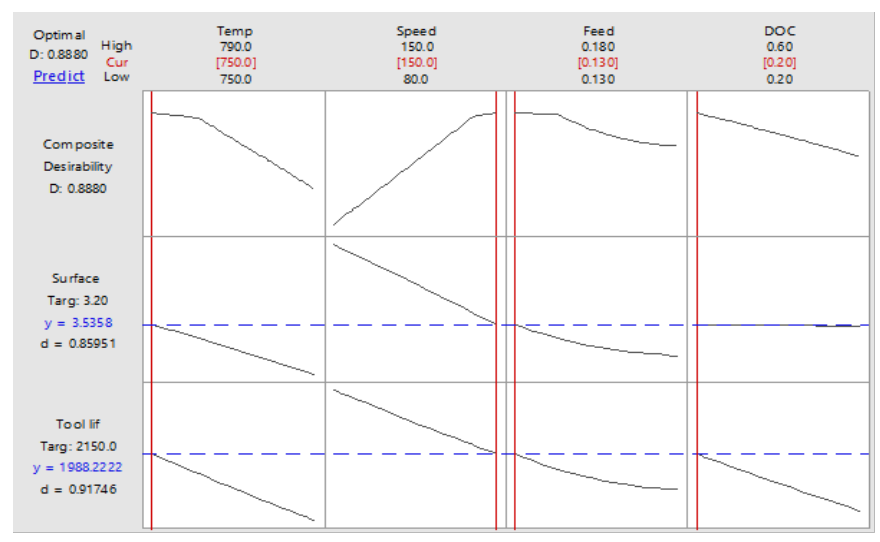

Figure 5: Response surface plots for TL and SR of AISI1040 F-B DPS 
optimum combination of $T_{L}$ and $S_{R}$ values RSM is used and values for different machining parameters are obtained. The composite desirability, D value of 0.8880 is near to 1 shows that the optimized results have good fit. Optimum $T_{L}$ and $S_{R}$ are observed in $750{ }^{\circ} \mathrm{C}$ treated DPS. Using corresponding speed, feed and DoC, confirmation test is carried out at the optimized parameter level to determine the feasibility of the model. Analysing both $T_{L}$ and $S_{R}$, experiment results $T_{L}$ as 1985 seconds and from RSM optimized parameter as 1988.2 seconds. This shows that actual and optimised values are closer and within the range. $S_{R}$ obtained by considering the optimized process parameters, the experimental value of SR is $3.50 \mu \mathrm{m}$ and optimized process result is $3.48 \mu \mathrm{m}$. Difference between these values is less than $5 \%$ error. Optimum $T_{L}$ and $S_{R}$ are observed at $750^{\circ} \mathrm{C}$ for F-B DPS AISI1040 steel.

\section{CONCLUSION}

The following conclusions are arrived at after conducting the heat treatment and machinability tests for AISI1040 ferrite-bainite dual phase steel

1. Regression equations obtained using the experimental results of machinability tests have high $R$ squared value, indicating the good fit. These equations may be used to predict the tool life and surface roughness for the machining operation of F-B medium carbon steels.

2. Microstructure reveals the ferrite - bainite relationship in which increase in the intercritical temperature has resulted in the increase in bainite phase.

3. Increase in the intercritical temperature has resulted in the improvement in the hardness for dual phase steel.

4. From the ANOVA results for tool life, it is seen that, for the ferrite bainite steel, depth of cut has $47.955 \%$ contribution on tool life, followed by temperature with $24.82 \%$ contribution. Speed has $26.705 \%$ relative contribution on tool life. Feed rate does not have significant effect on tool life within the range of values considered for this study.

5. Speed has major contribution with $54.29 \%$ on surface roughness, whereas temperature has $35 \%$ relative contribution on surface roughness. Feed and depth of cut have shown minimum effect on surface roughness of AISI 1040 ferrite bainite structure for the range of values considered for the study.

6. Optimum combination of higher tool life and lower surface roughness is observed at $750^{\circ} \mathrm{C}$ for F-B DPS AISI1040 steel.

\section{REFERENCES}

1. Lalbondre, R., Krishna. P, Mohankumar, G. C. (2014). An experimental investigation on machinability studies of steels by face turning. Procedia materials science, vol.6, 1386-1395. doi.org/10.1016/j. proeng.2013.09.138

2. Chandrasekaran H. and R. M'Saoubi (2006). Improved machinability in hard milling and strategies for steel development, CIRP Annals, vol. 55, no.1, 93-96. doi.org/10.1016/S0007-8506(07)60374-6

3. Songmene V., Khettabi, R. and Kouam, J., (2012). Dry High-Speed Machining: A Cost Effective \& Green Process, Int. J. Manufacturing Research (IJMR), vol.7, no.3, 229-256, 10.1504/IJMR.2012.048695

4. Hegde A, Sharma, S, (2018). Machinability study of manganese alloyed austempered ductile iron. Journal of the Brazilian Society of Mechanical Sciences and Engineering, vol. 40, 338. doi.org/10.1007/ s40430-018-1258-6

5. Yellowley, I., Lai, C. T. (1993). The use of force ratios in the tracking of tool wear in turning. Journal of Manufacturing Science and Engineering, vol. 115, no.3, 370-372, doi.org/10.1115/1.2901676

6. Hegde A, Sharma, S, (2018)). Comparison of machinability of manganese alloyed austempered ductile iron produced using conventional and two step austempering processes. Materials Research Express, vo. 5, no.5, 056519, doi.org/10.1088/20531591/aac254

7. Boubekri, N., Rodriguez, J., Asfour, S. (2003). Development of an aggregate indicator to assess the machinability of steels. Journal of Materials Processing Technology, 134(2), 159-165, 10.1016/S09240136(02)00446-6

8. N. R. Dhar, S. Paul, A. B. Chattopadhyay (2002). Machining of AISI 4140 steel under cryogenic cooling - Tool wear, surface roughness and dimensional deviation. Journal of Materials Processing Technology, vol. 123, no.3, 483-489. doi: 10.1016/S09240136(02)00134-6.

9. I. Asiltürk and H. Akkuş (2011). Determining the effect of cutting parameters on surface roughness in hard turning using the Taguchi method. Measurement, vol. 44, no.9, 1697-1704, doi: 10.1016/j.measurement..07.003.

10. P. L. Anand, S.Shivade, Shivraj Bhagat, Suraj Jagdale, Amit Nikam (2014). Optimization of machining parameters for turning using taguchi approach. International Journal of Recent Technology and Engineering, vol. 3, no.1, 145-149, doi: 10.13140/2.1.1515.6801

11. ISO 3685 (1993), "Standard for tool life testing with single point turning tools," 
12. ISO 4287 (1997), "Geometrical Product Specifications (GPS) -- Surface texture: Profile method -Terms, definitions and surface texture parameters," Int. Organ. Stand.

13. Gurumurthy, B.M., Gowrishankar, M.C., Sharma, S.,Shettar, M., Hiremath, P. (2020). Microstructure authentication on mechanical property of medium carbon Low alloy duplex steels. Journal of Materials Research and Technology, vol.9, no.3, S105-S111, doi.org/10.1016/j.jmrt.2020.03.027.
14. M. Nalbant, H. Gökkaya, and G. Sur (2007). Application of Taguchi method in the optimization of cutting parameters for surface roughness in turning. Materials \& Design, vol. 28, no.4, 1379-1385. doi. org/10.1016/j.matdes.2006.01.008.

15. K. K. Alaneme, O. J. Adejumo, and J. O. Borode (2013). Influence of different cyclic intercritical heat-treatment schedules on the microstructure and mechanical behaviour of a dual phase medium carbon low alloy steel. Metallurgical and Materials Engineering, vol. 19, no. 2, 155-166. 